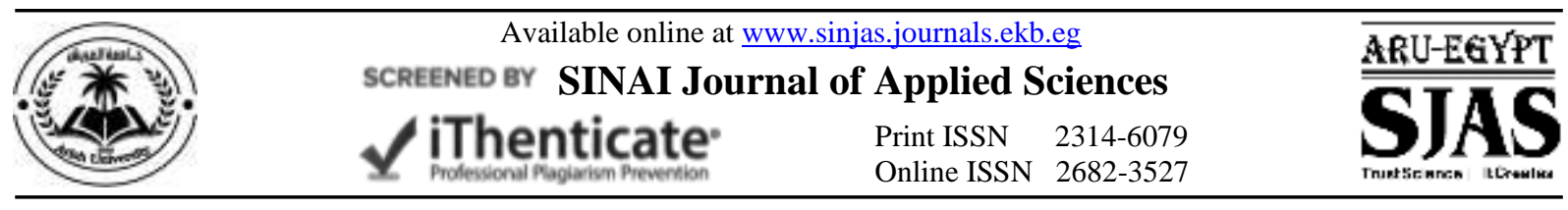

\title{
STATISTICAL MEASUREMENT OF THE PRODUCTION FUNCTIONS FOR CANTALOUPE CROP IN NORTH SINAI GOVERNORATE
}

\author{
Esraa M.K. El-Shereif ${ }^{* 1}$, Mohamed A. ElSayed ${ }^{2}$ and Soad A. Ibrahim ${ }^{2}$ \\ 1. Postgrad. Std. Dept. Econ. and Rural Develop., Fac. Environ. Agric. Sci., Arish Univ., Egypt. \\ 1. Dept. Econ. and Rural Develop., Fac. Environ. Agric. Sci., Arish Univ., Egypt.
}

\begin{tabular}{l} 
ARTICLE INFO \\
\hline Article history: \\
Received: $12 / 10 / 2020$ \\
Revised: 08/11/2020 \\
Accepted: $02 / 12 / 2020$ \\
Available online: $22 / 12 / 2020$ \\
\hline Keywords: \\
Cantaloupe crop, \\
production efficiency, \\
production function, \\
productive elasticity.
\end{tabular}

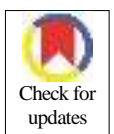

\begin{abstract}
The study aimed at analyze the production and economic efficiency of the cantaloupe crop, the results of the statistical measurement of the production functions of the winter cantaloupe crop showed in the total sample farms, found that the municipal fertilizer factor (chick) occupies the first place of effect on the production quantity of the cantaloupe crop, the chemical fertilizer factor ranked second, then the pesticide quantity factor in the third order, and finally the number of seedlings factor The value of the modified determination coefficient indicates that about $76 \%$ of the changes, as well as estimates that the productivity elasticity amounted to about $0.208,0.415$, 0.105 and 0.153 respectively. The results of the summer cantaloupe that the municipal fertilizer factor (chick) ranks first in terms of affecting the quantity of the cantaloupe crop, followed by the number of seedlings factor in the second place, then the chemical fertilizer factor in the third place and finally the factor of the human labor volume in the fourth place and last. The value of the modified determination coefficient indicates that about $84 \%$ of the changes in the quantity of production are due to the change in the aforementioned factors. It is also estimated that the productivity elasticity amounted to about $0.214,0.415,0.131$ and 0.123 respectively.
\end{abstract}

\section{مشكنة البحث}

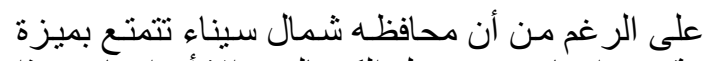

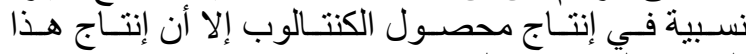

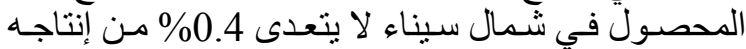

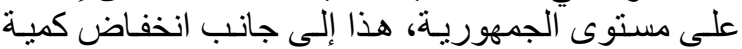

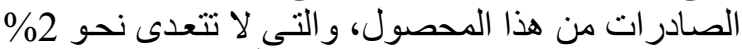

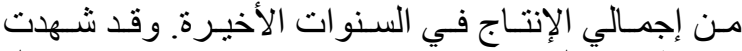

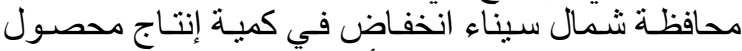

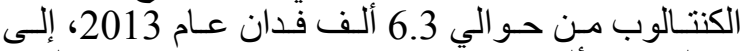
حو الي 5.7 ألف فدان، عام 2016، ونس بنسبة انخفاض بلغت

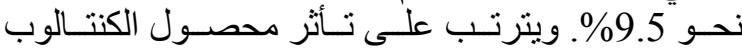

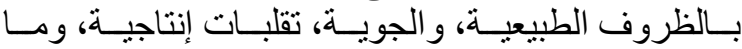

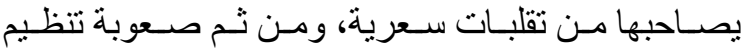
المعروض من الإنتاج بما يتناسب مع الطلب عليه ليه أهداف البحث

يهدف البحث بصفة عامسة إلى در اسـة وتحليل الكفـاءة

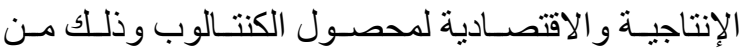

\section{مقدمة}

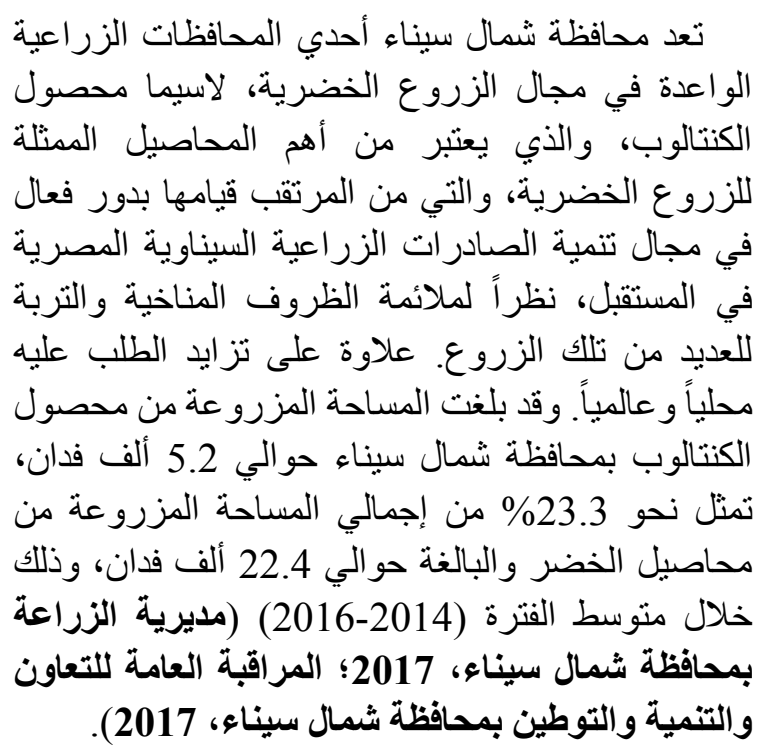

* Corresponding author: E-mail address: esraalshrf@gmail.com https://doi.org/ 10.21608/SINJAS.2020.46063.1007

(C) 2020 SINAI Journal of Applied Sciences. Published by Fac. Environ. Agric. Sci., Arish Univ. All rights reserved. 
داخل مختلف المر اكز الإدارية بشمال سيناء خلال متوسط الفترة (2014-2016). ومنه يتبين أن مركز العريش العريش يحتل المرتبة الأولى بين مراكز المئه المحافظة بالنسبة النية

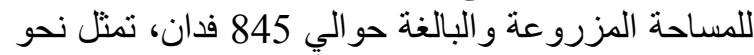

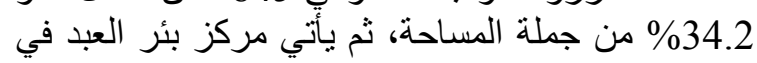

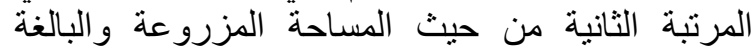

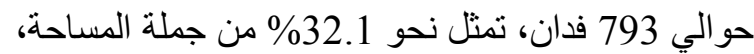
ثم يأتي مركز الثيخ زويد في المرتبة الثالثة، حيث جلثة بلغت الماحة

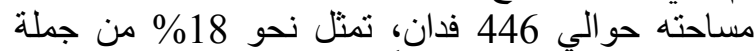

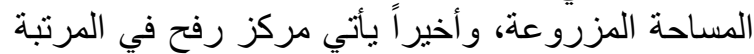

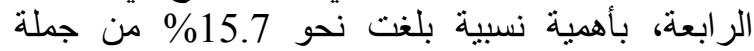
المساحة المزروعة والبالغة حوالي 2474 فدان وذلان خلال متوسط الفترة (2014-2016).

التقدير الإحصائي لاوال إنتاج محصول الكنتالوب الثتوي بعينة الاراسة الاستة

يستعرض هذا الجزء من الدراسة نتائج التقدير

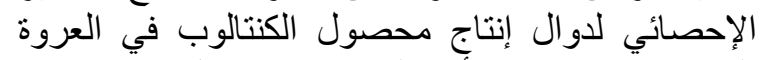

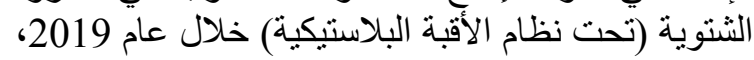

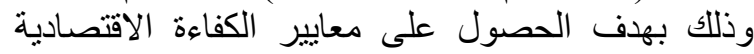
للاستخدام الأمثل للموارد الإنتاجية الزر اعية.

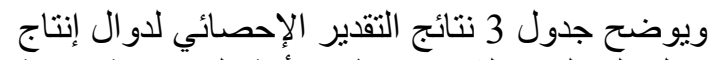
محصول الكنتالوب الثنتوي (نظام الأقبة البالانتيكية) بعينة

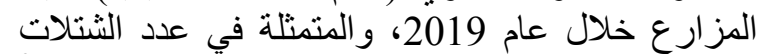

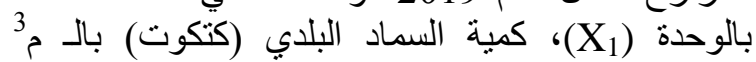
(X)

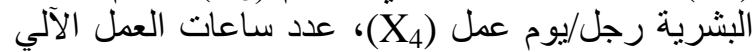

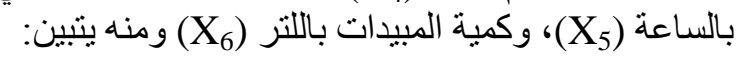

\section{الفئة الأولى (أقل من فدان)}

توضح المعادلة رقم (1) بجدول 3 التقدير القياسي لدالة إنتاج محصول الكنتالوب الثابة الثتوب (نظام الاقبة

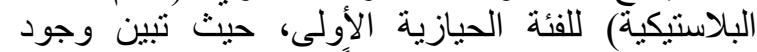

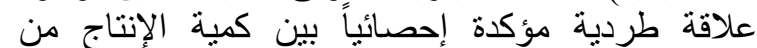

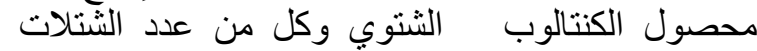

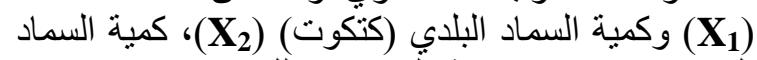
الكيماوى (X)

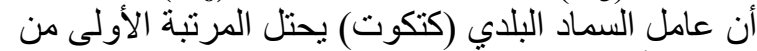

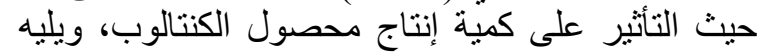

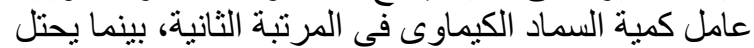
عامل عدد الثتلات (X) المرتبتين الثالثة والر ابعة على الترتيب. كما تشير التير

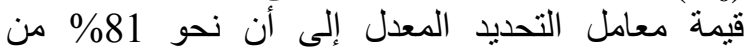

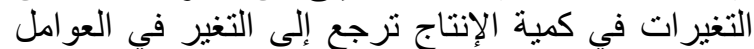

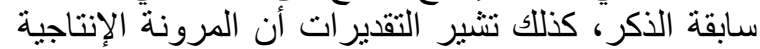

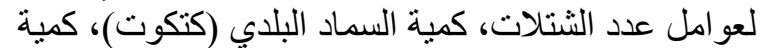

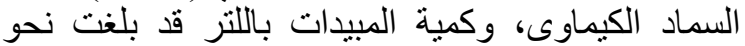
0.216، 0.285، 0.163، 0.067 على الترتيب، أب أن الن بل

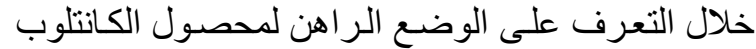

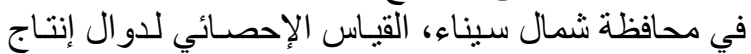

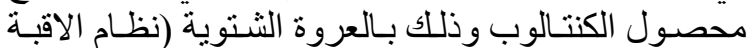
البلاستيكية)، و الصيفية، وذلك خلال عام 2019.

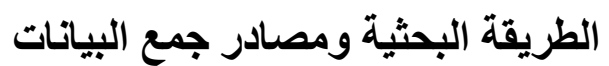

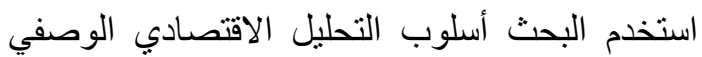

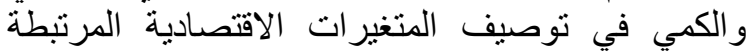

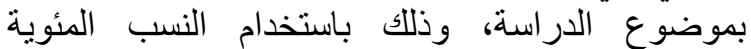

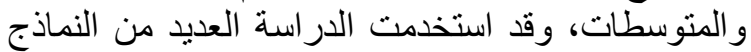

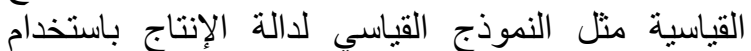

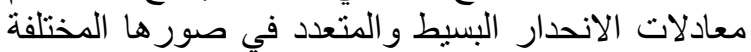

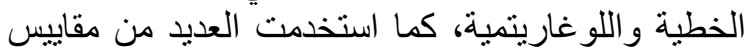

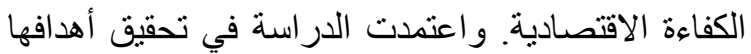

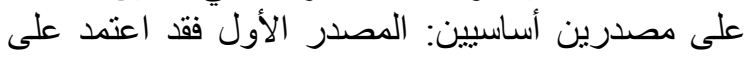

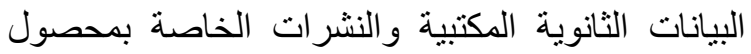

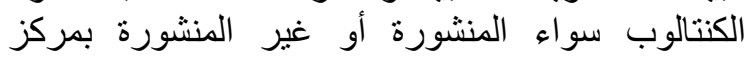

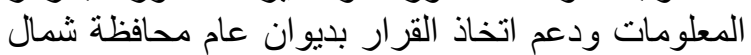

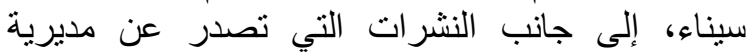

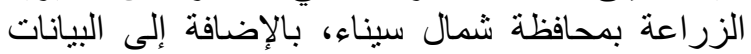

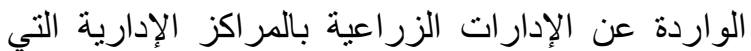
تناولتها عينة الدر اسة.

أما المصدر الثاني اعتمد على البيانات الأوليـة لعينة

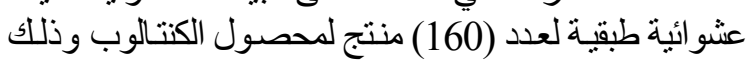

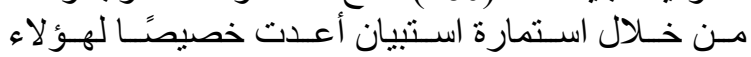

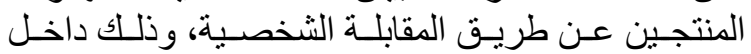
مركزى العريش وبئر العبد خلال عام العقابل الشن 2019.

\section{النتائج ومناقشتهها}

\section{الأهمية النسبية لمحصول الكنتالوب داخل قائمة

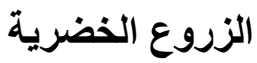

باستعر اض الأرقام الواردة بجدول 1 ينتين أن محصول

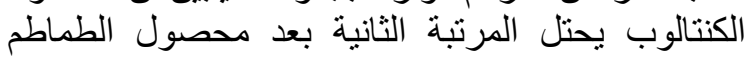

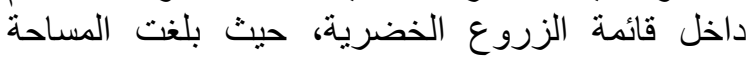

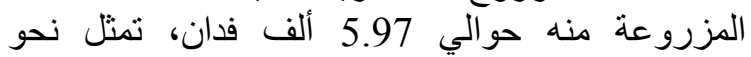

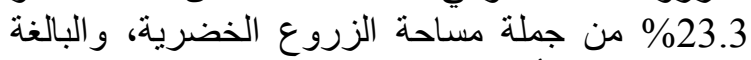
حوالي 22,42 ألف فدان، خلال متوسط الفترة (2014-

المنظور الاقتصادي لمحصول الكانتلوب الثتوي (نظام الأقبة البلاستيكية) في محافظة شمال سيناء الأيول

الأهمية النسبية للمساحة المزروعة المبلة بمحصول

الكنتالوب الثتوى داخل المراكز الإدارية بمحافظة بمدية شمال سيناء

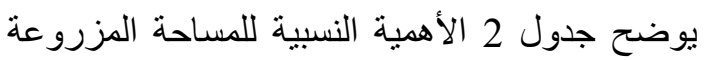
بمحصول الكنتالوب الثتوي (نظام الاقبة البلاستيكية) 
جلول 1. الأهمية النسبية لمحصول الكنتالوب داخل قائمة الزروع الخضرية في محافظة شمال سيناء خلال متوسط الفترة

(2016-2014)

\begin{tabular}{|c|c|c|c|c|c|}
\hline$(\%)$ & المساحة بالفدان & المحصول & $(\%)$ & المساحة بالفدان & المحصول \\
\hline 2.34 & 524 & بطاطس & 41.65 & 9335 & طماطم \\
\hline 1.59 & 356 & بطيخ مسقاوي & 23.26 & 5213 & كاتتلوب \\
\hline 0.95 & 214 & بسلة " بل & 9.40 & 2107 & خيار \\
\hline 0.71 & 160 & بامية & 7.23 & 1620 & باذنجان \\
\hline 0.32 & 72 & ملوخية & 6.48 & 1452 & كوسة \\
\hline 0.20 & 45 & كرنب & 5.88 & 1317 & فلفل \\
\hline 100.0 & 22415 & & & الإجمالي & \\
\hline
\end{tabular}

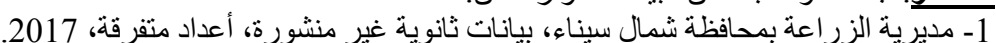
2- المر اقبة العامة للتعاون و التنمية و التوطين بمحافظة شمال سيناء، بيانات ثانوية غير منشورة، أعداد متفرقة، 2017.

جدول 2. الأهمية النسبية للمساحة المزروعة لمحصول الكانتلوب الثتوي (نظام الاقبة البلاستيكية) داخل مختلف المر اكز الإدارية وجملة المحافظة في شمال سيناء خلال متوسط الفئل الفترة (2014-2016)

\begin{tabular}{|c|c|c|}
\hline الأهمية النسبية (\%) & المساحة المزروعة (فذان) & المراكز الإدارية \\
\hline 34.2 & 845 & العريش \\
\hline 32.1 & 793 & رفح \\
\hline 18.5 & 446 & الشيخ زويد \\
\hline 15.7 & 390 & بئر العبد \\
\hline- & - & الحسنة \\
\hline 100 & 2474 & إجمالي المحافظة \\
\hline
\end{tabular}

جدول 3. نتائج القياس الإحصائي لدوال إنتاج محصول الكتتالوب الثتوي (نظام الاقبة البلاستيكية) داخل مختلف الفئات الحيازية وجملة العينة خلال عام لإن إنتاج 2019.

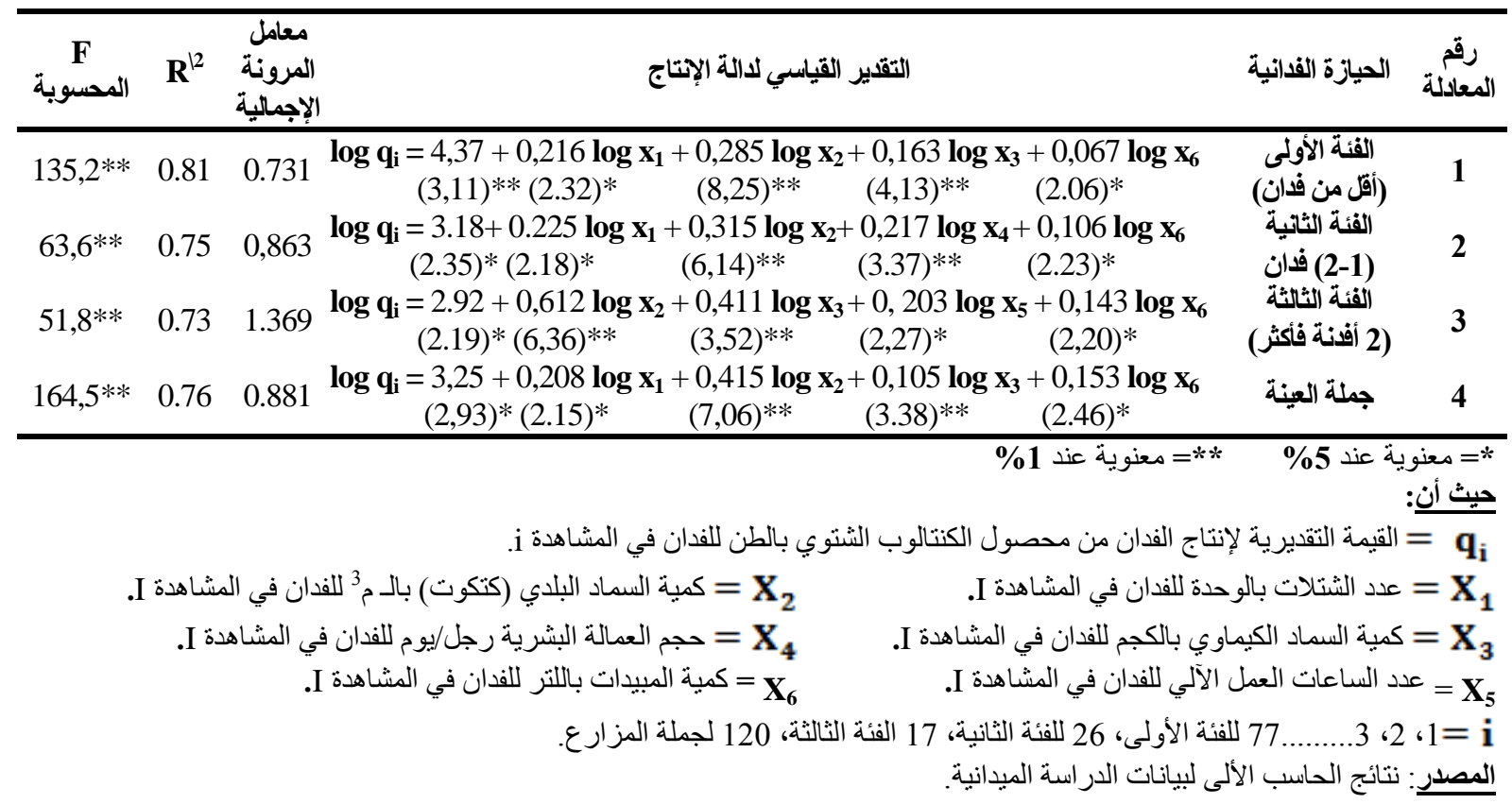


محصول الكتنالوب الثنتوي وكلاً من كميـة السماد البلدي

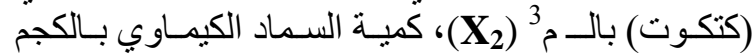
الع (X)

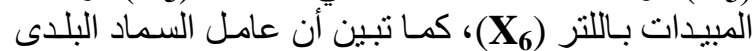

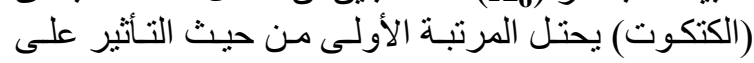

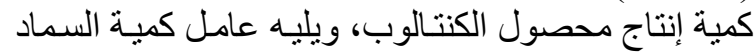

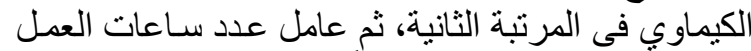

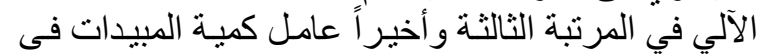

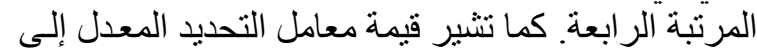

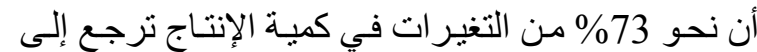

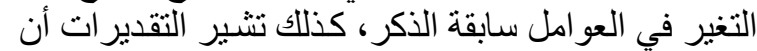

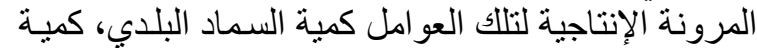

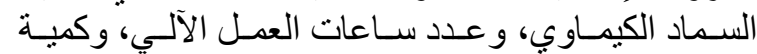

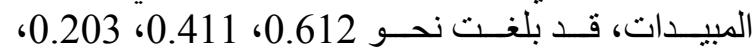

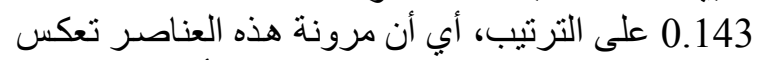

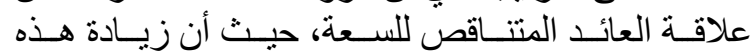

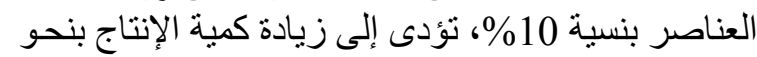

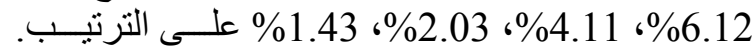

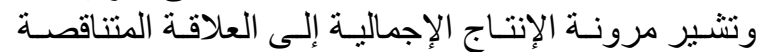

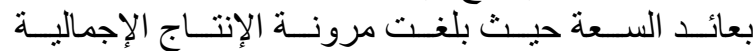

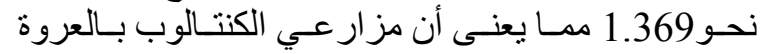

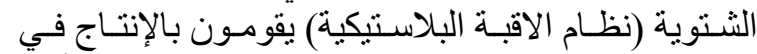

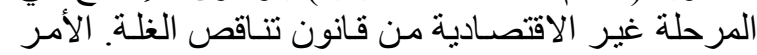

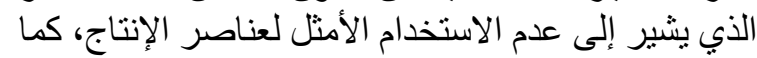

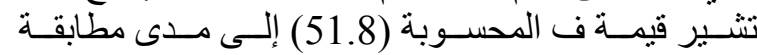
النموذج المستخدم لطبيعة البيانات موضع القياس.

\section{جملة مزارع العينة}

تثشير المعادلة رقم (4) بجدول 3 إلى التقدير القياسي

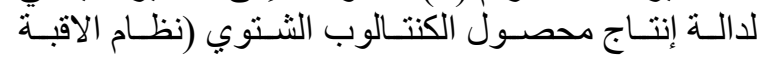

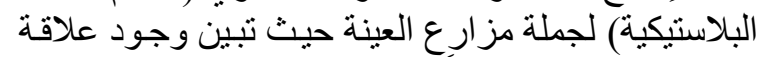

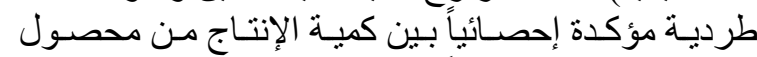

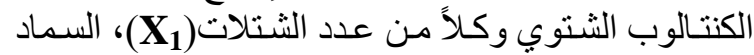

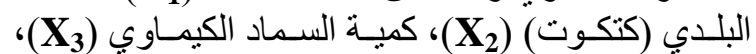

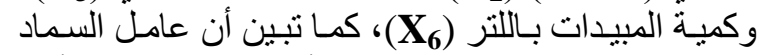

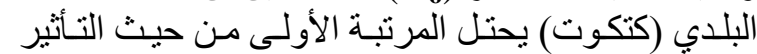

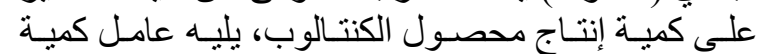

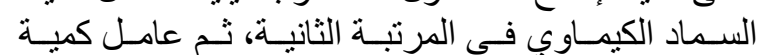

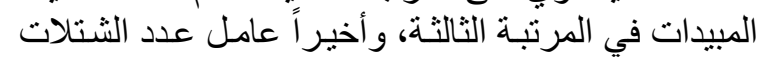

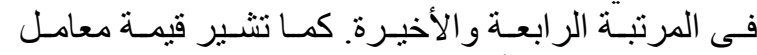

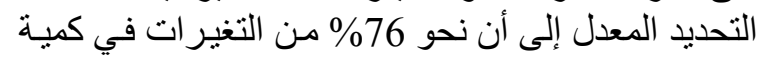

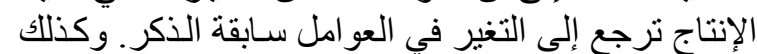

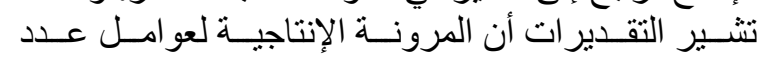

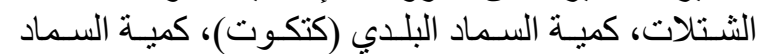

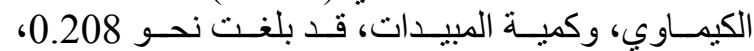

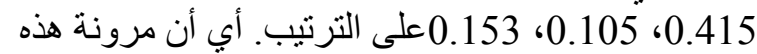

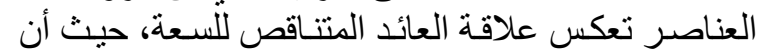

مرونــة هذه العناصـر تعكس علاقـة العائد المتنـاقص

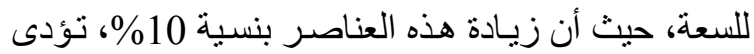

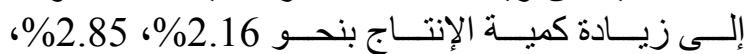

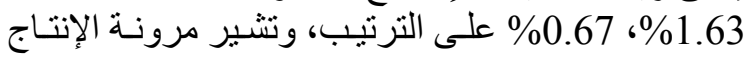

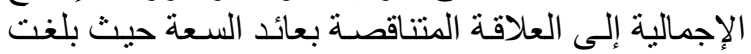

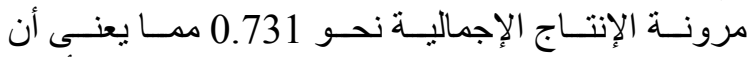

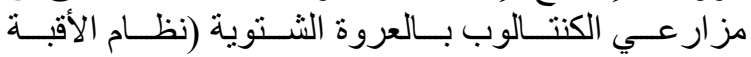

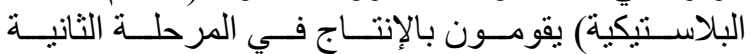

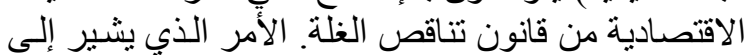

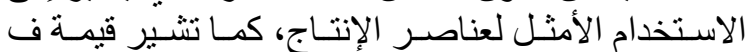

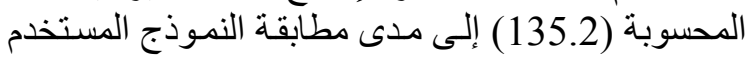
لطبيعة البيانات موضع القياس. الفئة الثانية (1- 2) فدان

تبين المعادلة رقم (2) بجدول 3 التقدير القياسي لدالة

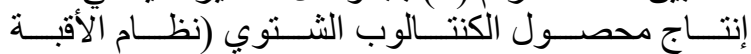

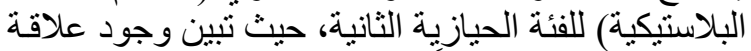

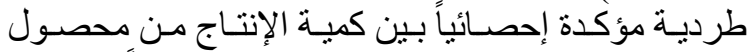

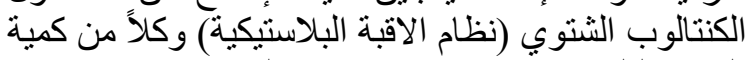

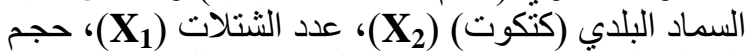

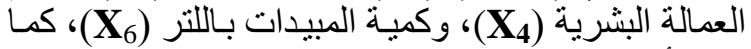

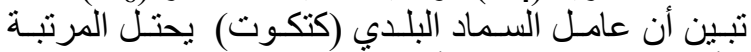

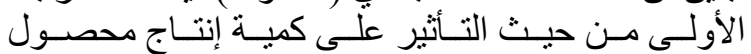

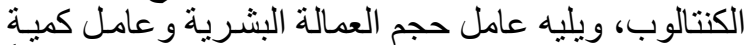

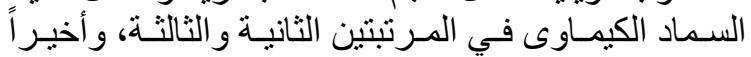

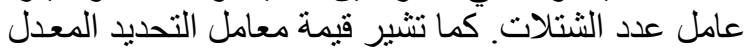

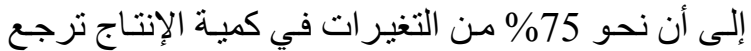
إلى التغير في العو امل سابقة الذكر ، كذلك تشير التير التقدير التيرات

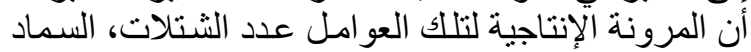

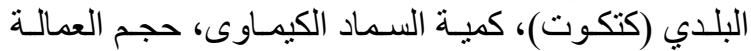

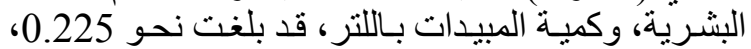

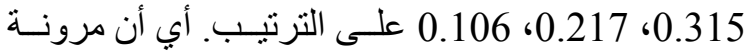

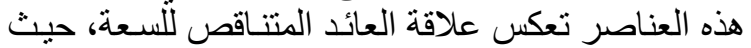

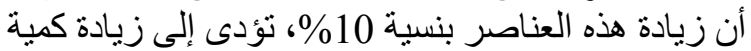

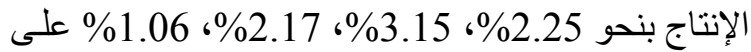

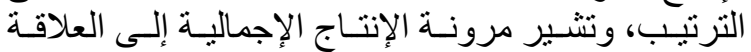

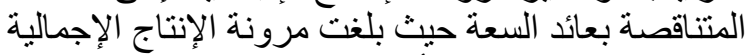

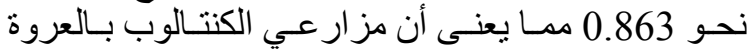

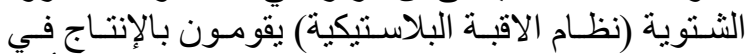

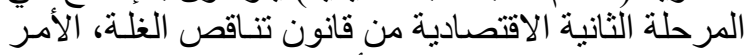

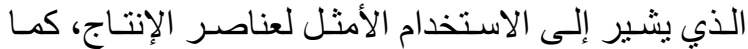

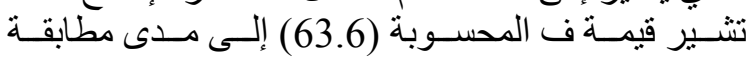
النموذج المستخدم لطبيعة البيانات موضع القياس.

\section{الفئة الثالثة (2 أفنة فأكثر)}

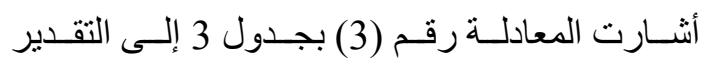

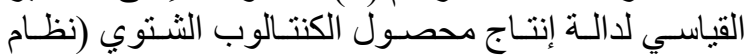

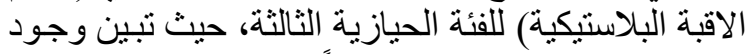

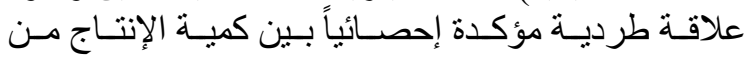


التقدير الإحصائي لاوال إنتاج محصول الكنتالوب الصيفي بعينة الاراسة الإسة

ويوضح جدول 6 نتائج التقدير الإحصائي لدوال إنتاج المباج

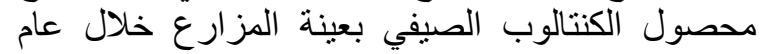

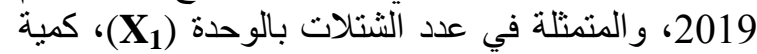

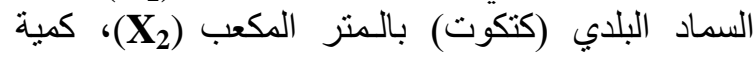

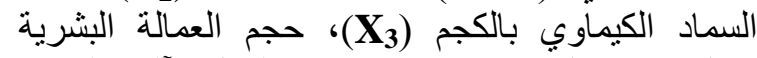

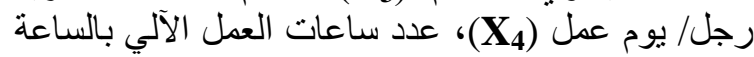
(

\section{الفئة الأولى (أقل من فدان)}

توضـح المعادلة رقم (5) التقدير القياسي لدالـة إنتاج

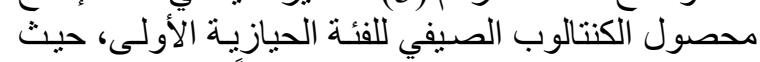

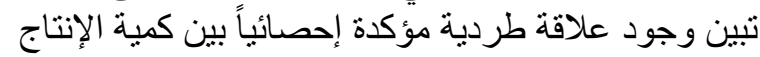

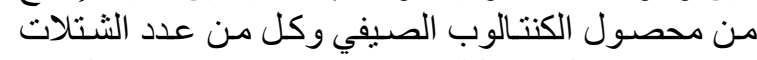

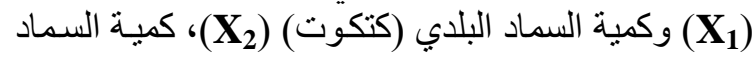

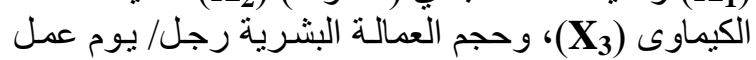

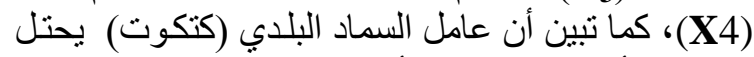

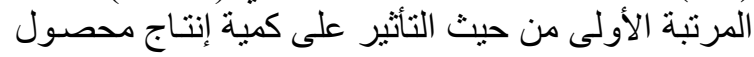

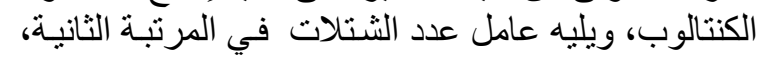

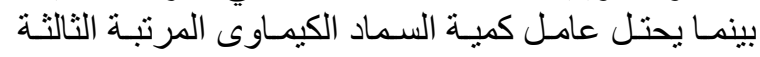

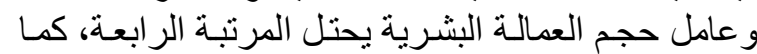

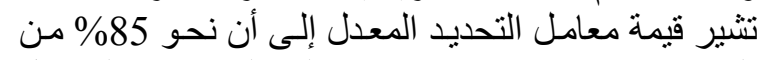

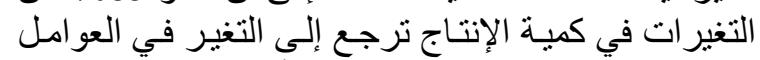

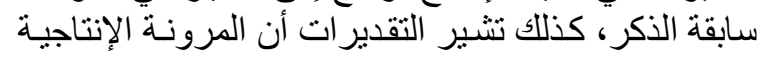

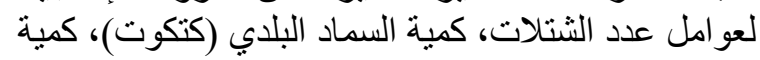

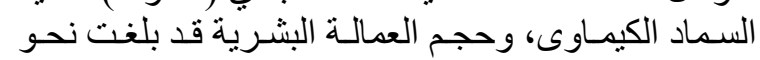

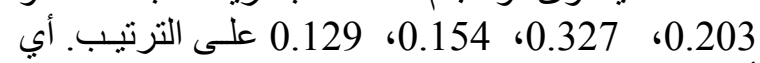

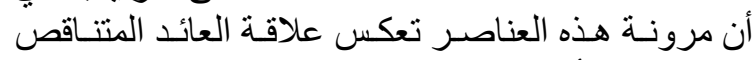

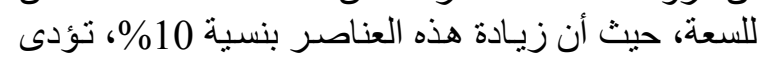

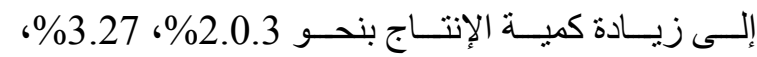

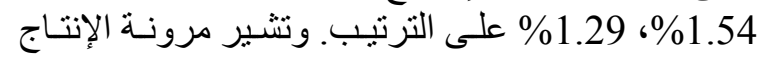

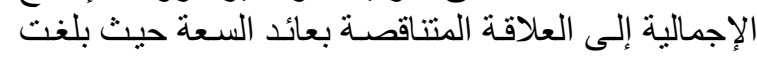

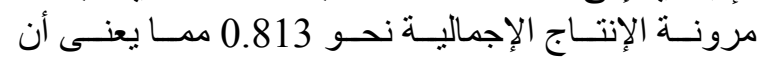

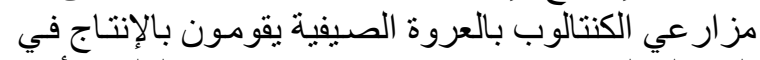

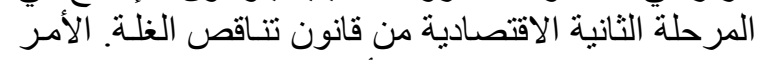

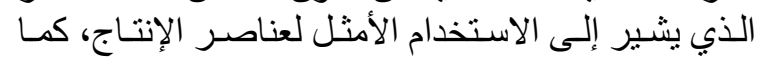

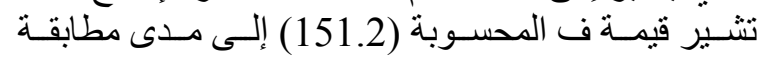
النموذج المستخدم لطبيعة البيانات موضع القياس.

\section{الفئة الثانية (1- 2 2) فدان}

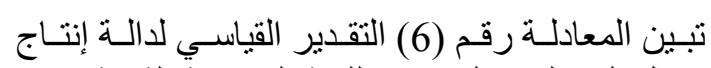

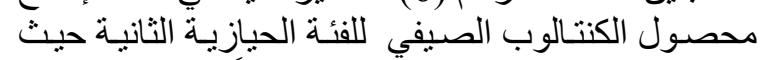

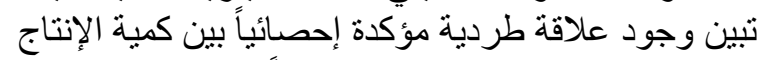

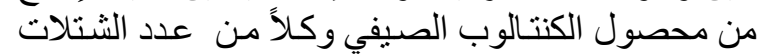
(X)

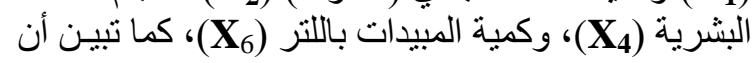

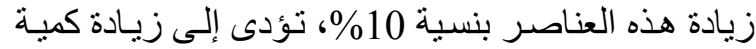

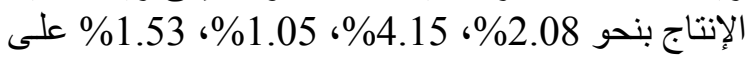

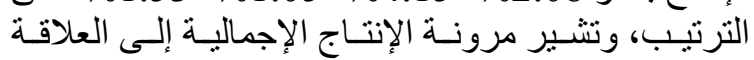
المتناقصة بعائد السعة حيث بلغت مرون الإن الإنة الإنتاج الإجمالية العالية

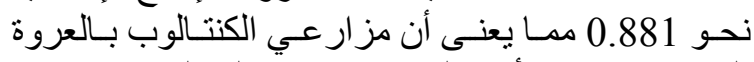

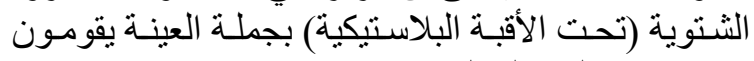

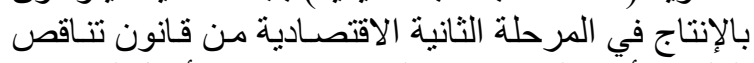

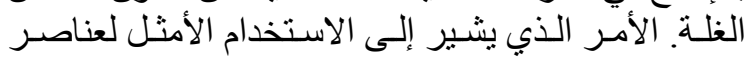

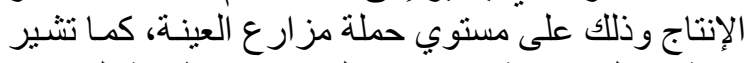

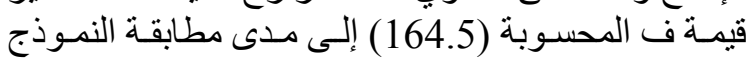
المستخدم لطبيعة البيانات موضع القياس.

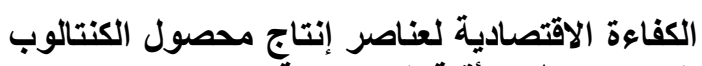

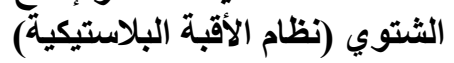

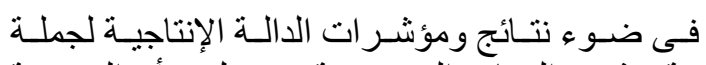

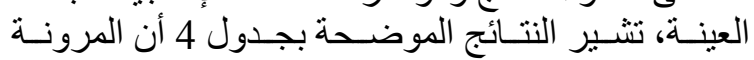

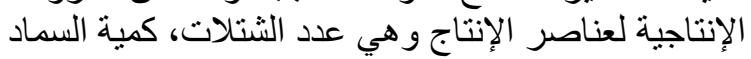

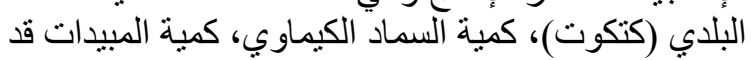

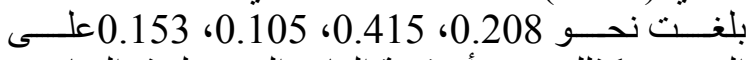
ألترتيب، كذللك يتبين أن قيمة الناتج الحدي لهذه العناصـ

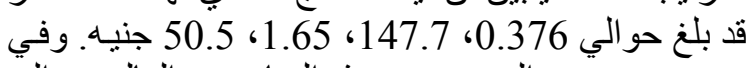

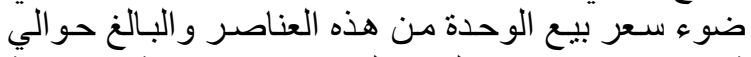

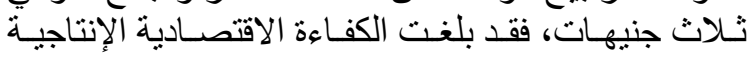
لعناصر الإنتاج عدد الثتنات، النيات السماد البلدي (كتكوت)،

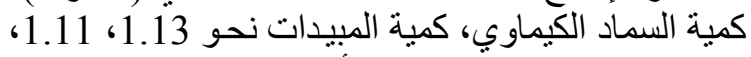

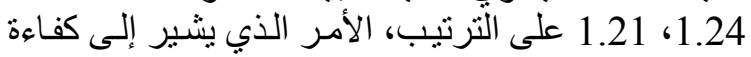
استخدام هذه العناصر. 1.24 الترت.

\section{المنظور الاقتصادي لمحصول الكاتتلوب الصيفي في محافظة شمال سبناء الأهن}

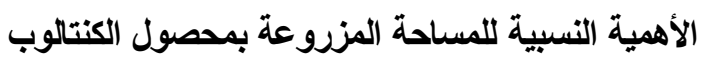
الصيفي داخل المر اكز الإدارية بمحافظة شمال سينة سيناء

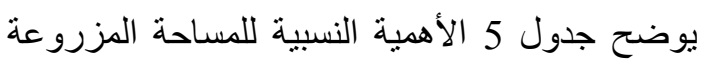

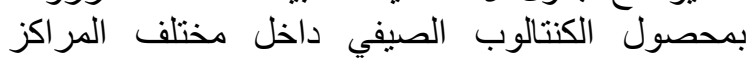

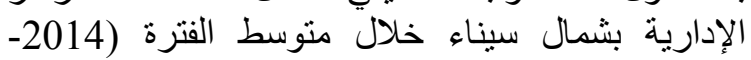

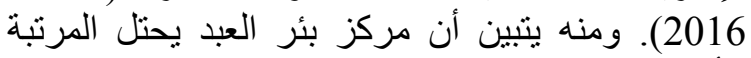

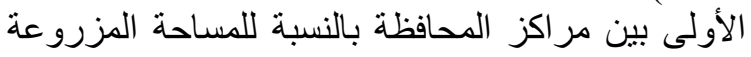

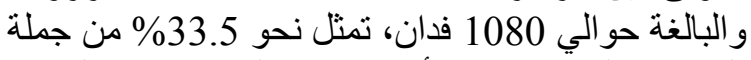

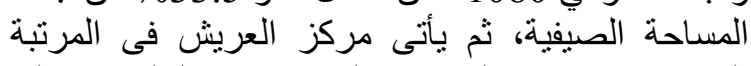

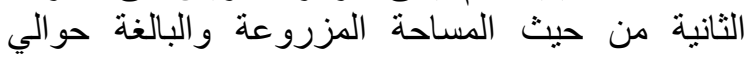

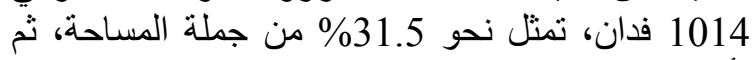

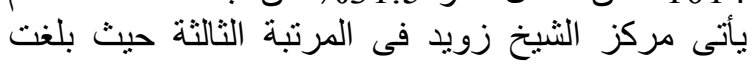

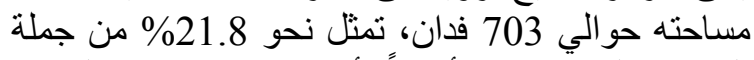

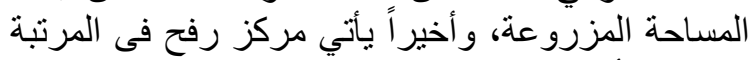

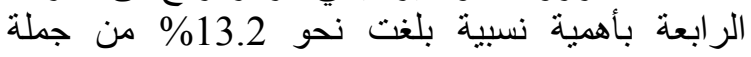
المساحة المزروعة والمية فية البالغة حوالي 3223 فدان وذلك خلال منوسط الفترة (2014-2016). 
جلول 4. الكفاعة الاقتصادية لعناصر إنتاج محصول الكنتالوب فى العروة الثتوية (تحت الأقبة البلاستيكية) داخل جملة مزارع العينة خلال عام 2019

\begin{tabular}{|c|c|c|c|c|c|c|c|}
\hline الاقتصادية & 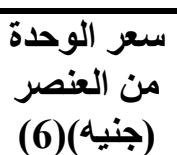 & قالحدية (الناتج) & 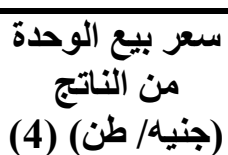 & 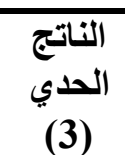 & $\begin{array}{c}\text { المتوسط } \\
\text { (2) }\end{array}$ & الإنتاجية & العناصر الإنتاجية \\
\hline 1.127 & 1.00 & 1.127 & 3.00 & 0.376 & 1.808 & 0.208 & عدد الثتلات (X1) (شتلة) \\
\hline 1.108 & 400.00 & 443.2 & 3.00 & 147.73 & 355.983 & 0.415 & السماد البلدى (X) (X) (X) \\
\hline 1.236 & 4.00 & 4.944 & 3.00 & 1.648 & 15.695 & 0.105 & الأسمدة الكيماوية (X) (كجم) \\
\hline 1.212 & 125.00 & 151.5 & 3.00 & 50.5 & 330.065 & 0.153 & كمية المبيدات (X) (لتر) \\
\hline
\end{tabular}

جذول 5. الأهمية النسبية للمساحة المزروعة لمحصول الكنتالوب الصيفي داخل مختلف الفئات الحيازية وجملة المحافظة في شمال سيناء خلال متوسط الفترة (2014-2016)

\begin{tabular}{|c|c|c|}
\hline الأهمية النسبية (\%) & المساحة المزروعة (فذان) & المراكز الإدارية \\
\hline 33.5 & 1080 & بئر العبد \\
\hline 31.5 & 1014 & العريش \\
\hline 21.8 & 703 & الشيخ زويد \\
\hline 13.2 & 426 & رفح \\
\hline- & - & 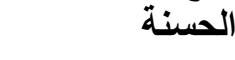 \\
\hline 100 & 3223 & إجمالي المحافظة \\
\hline
\end{tabular}

المصدر: جُمعت وحُسبت من الأرقام الواردة بجدول 2 بالملحق.

جذول 6. نتائج القياس الإحصائي لاوال إنتاج محصول الكنتالوب الصيفي داخل مختلف الفئات العيازية وجملة العينة خلال عام 2019

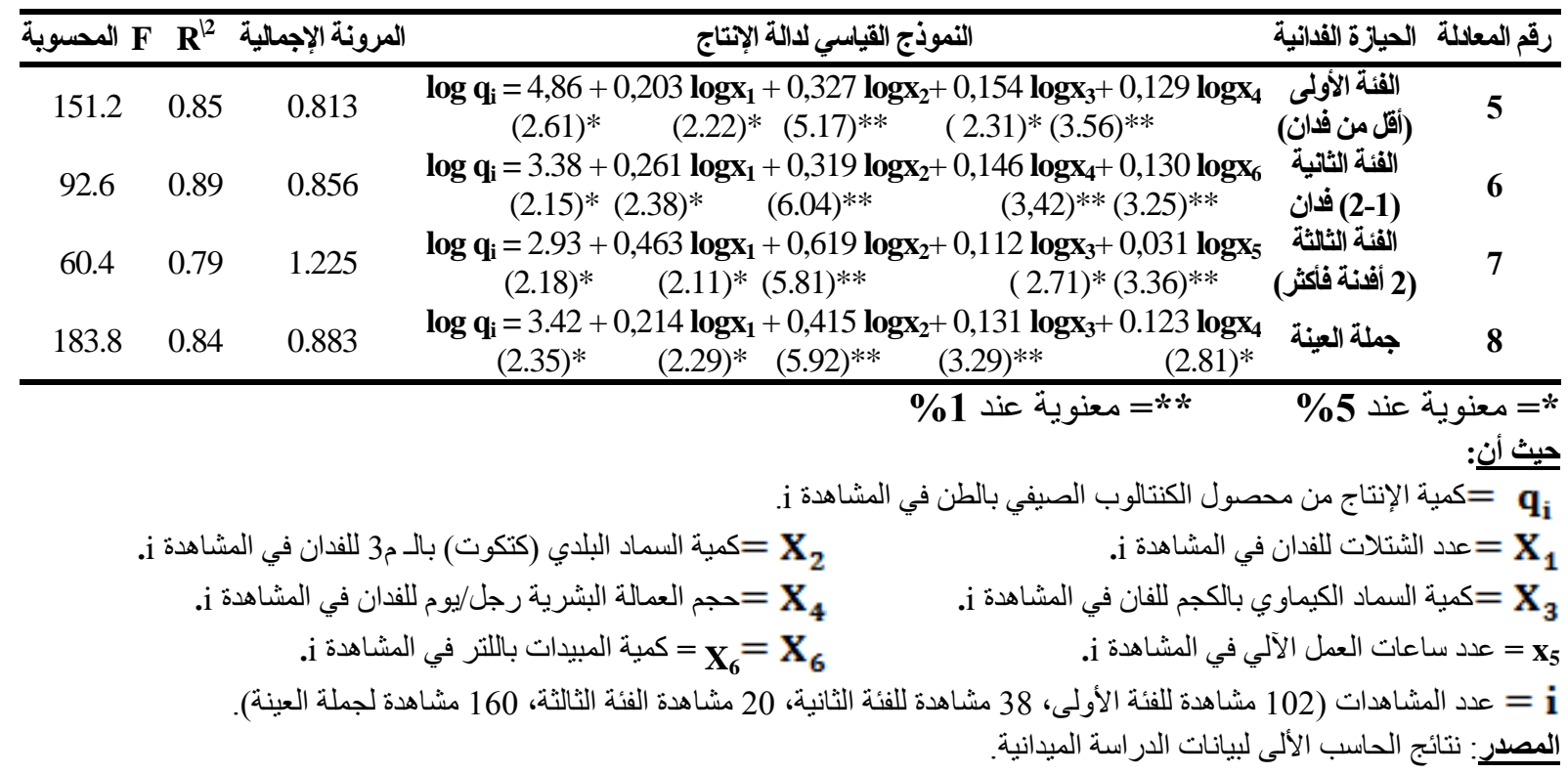


نحو 1.225 مما يعنى أن مزارعي الكنتالوب بالعروة

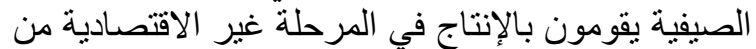
قانون تناقص الغلة. الأمر الذي يثنير إلى الذي عدم الاستخدام

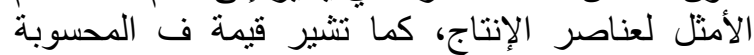
(60.4) إلى مدى مطابقة النموذج المستخدم لطبيعة

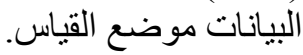
جملة مزارع العينة

تثشير المعادلة رقم (8) إلى التقدير القياسي لدالة إنتاج

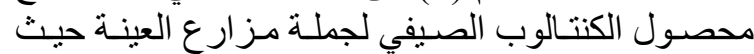
تبين وجود علاقة طردية مؤكدة إحصائياً بين كمية الإنتاج العين

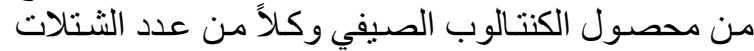

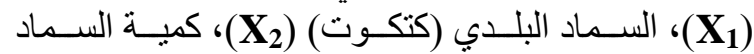

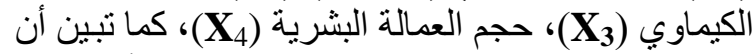

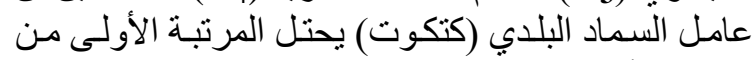

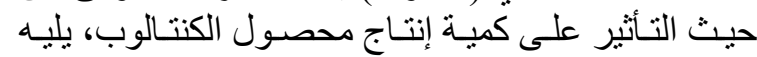

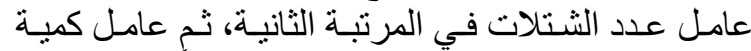

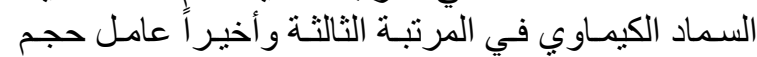

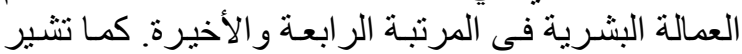

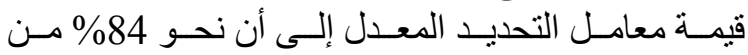
التغير ات في كميـة الإنتاج ترجع التعد إلى التغير في العوامل

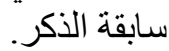

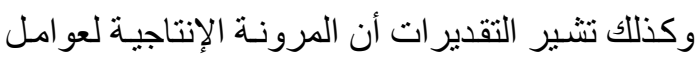

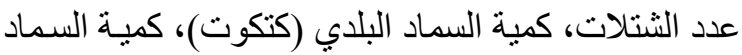

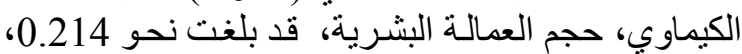

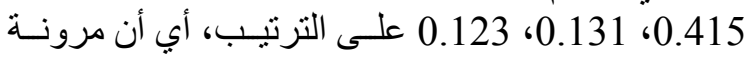

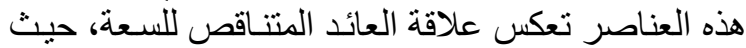

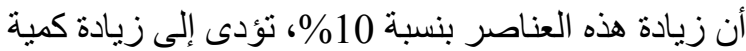

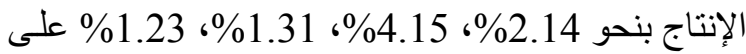

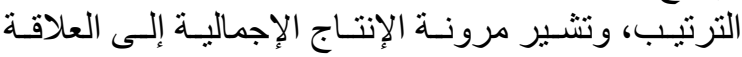
المتناقصة بعائد السعة حيث بلغت مرونة الإنتاج الإحتاج الإجمالية الإلية

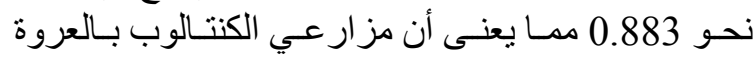

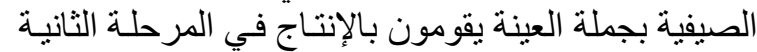

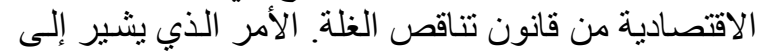

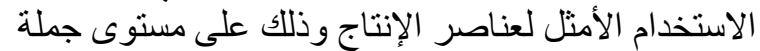

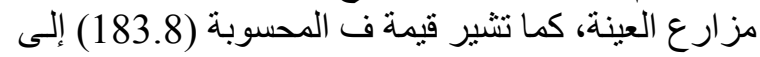

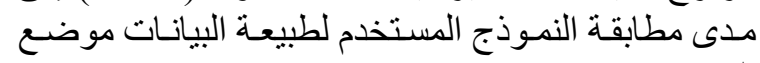

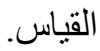

\section{الكفاءة الاقتصادية لعناصر إنتاج محصول الكنتالوب}

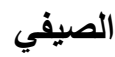

فى ضوء نتائج ومؤشرات الدالة الإنتاجية لجملة

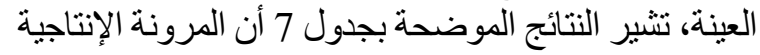

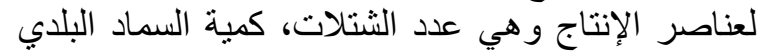

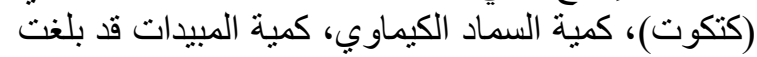

نحو 0.214، 0.415، 0.131، 0.123 على الترتيب.
عامل السماد البلدي (كتكوت) يحتل المرتبـة الأولى من الكن

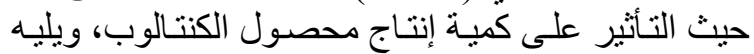

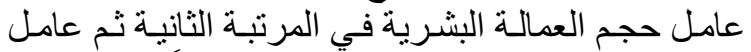

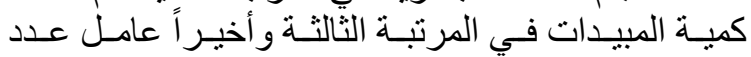

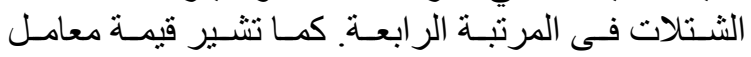

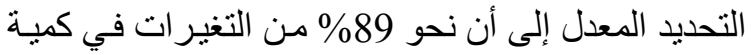

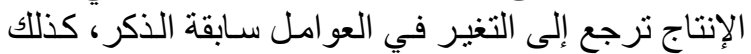

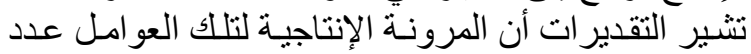
الشتلات، السماد البلدي (كتكوت)، حجم العمالة البشرية، البتانة

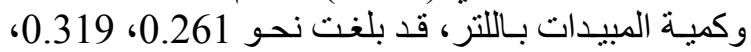

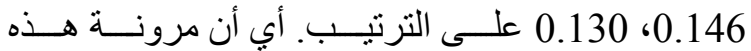

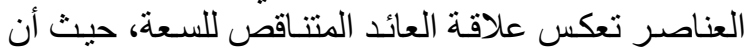

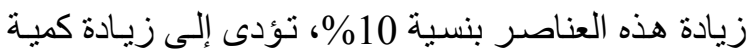

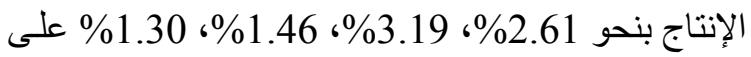

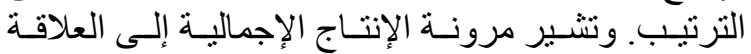

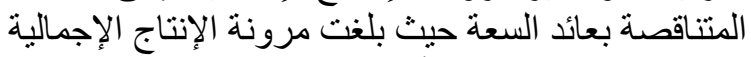

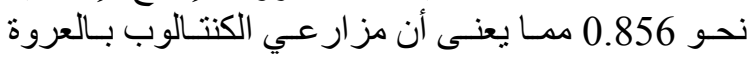

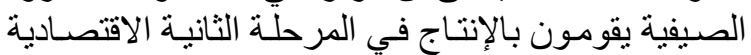
من قانون تناقص الغلـة، الأمر الذي يشير الإلى الإلى الإستخدام

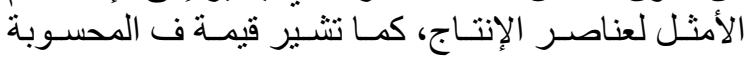

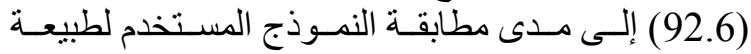
البيانات موضع التقدير.

الفئة الثالثة (2 أفدنة فأكثر)

أشنارت المعادلة رقم (7) إلى التقدير القياسي لدالة

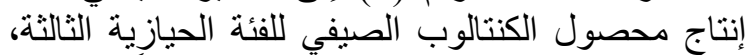
حيث تبين وجود علاقة طردية مؤكدة إحصائياً بين كمية الإنية

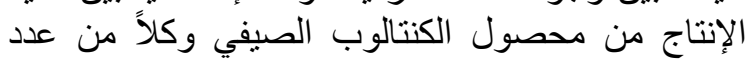

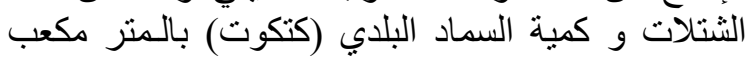
(X)

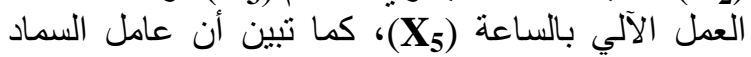

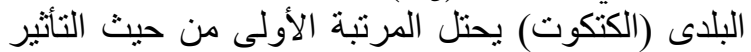

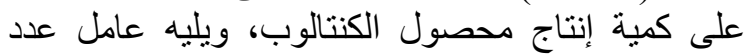

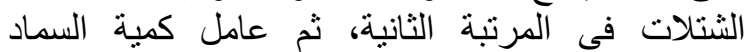

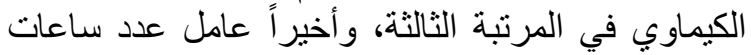

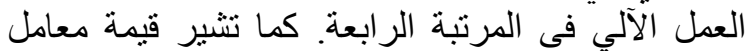
التحديد المعدل إلى أن نحو 79 \%

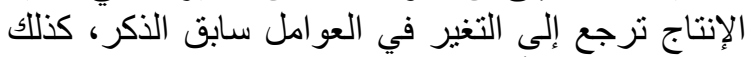

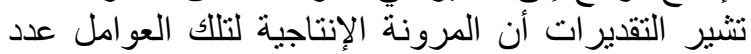

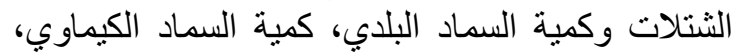

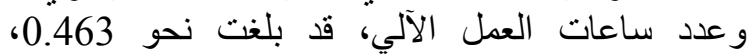
0.619، 0.112، 0.031 على الترلئ الترتيب، أي أن مرونة

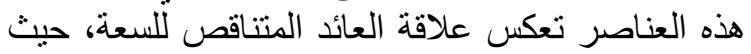

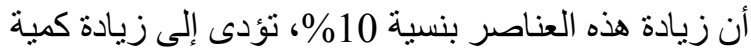

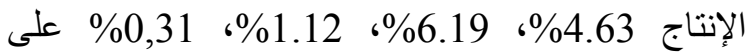
الترتيب، وتشير مرونة الإنتاج الإجمالية إلى العلاقة المتناقصة بعائد السعة حيث بلغت مرونة الإنتاج الإنتاج الإجمالية 


$$
\text { المراجع }
$$

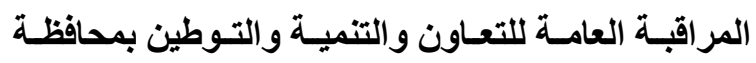

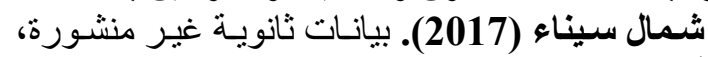

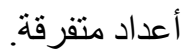
مديرية الزراعة بمحافظة شمال سيناء (2017). ثانوية غير منشورة، أعداد متفرقة. فئمال
كذلك يتبين أن قيمة الناتج الحدي لهذه العناصر قد بلغ

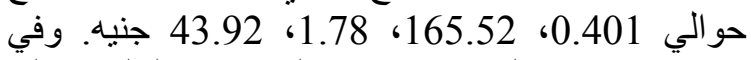
ضوء سعر بيع الوحدة من هذه العناصر والبالغ حوالي الئي 2.75جنيهاً، فقد بلغت الكفاءة الاقتصادية لعناصر العناه الإنتاج

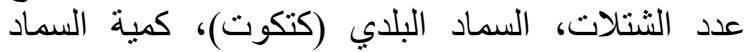

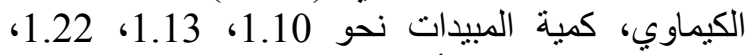
1.20 على الترتيب، الأمر الذي يشير إلى كفاءة استخدام

جدول 7. الكفاءة الاقتصادية لعناصر الإنتاج المستخدمة في زراعة محصول الكنتالوب الصيفي داخل مختلف الفئات الحيازية جملة العينة خلال عام الاعنة 2019

\begin{tabular}{|c|c|c|c|c|c|c|c|}
\hline $\begin{array}{c}\text { الاقتصادية } \\
\text { (7) } \\
\end{array}$ & سنر الوحدة & 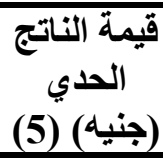 & 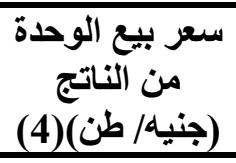 & $\begin{array}{c}\text { الحديتج } \\
\text { الناتي } \\
\end{array}$ & $\begin{array}{c}\text { المتوسط } \\
\text { الناتط } \\
\end{array}$ & الإنتاجية & العناصر الإنتاجية \\
\hline 1.102 & 1.00 & 1.102 & 2.75 & 0.401 & 1.874 & 0.214 & عدد الثتّلات (X) (شتلة) \\
\hline 1.138 & 400.0 & 455.2 & 2.75 & 165.527 & 398.86 & 0.415 & السماد البلدى (م²) (X) \\
\hline 1.225 & 4.00 & 4.90 & 2.75 & 1.782 & 13.603 & 0.131 & الأسمدة الكيماوية(X) (كجم) \\
\hline 1.208 & 100.0 & 120.8 & 2.75 & 43.927 & 357.13 & 0.123 & كمية المبيدات (X) (لتر) \\
\hline
\end{tabular}
$(6) \div(5)=(7) \quad$ (4) $\div(5)=(3) \quad$ (2) $(2) \div(3)=(1)$ المصدر: جُمعت وحُسبت من استمارات الاستبيان الخاصة بالدراسة الميدانية

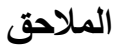

جدول 1. تطور المساحات المنزرعة من محصول الكاتتلوب الثتوى (نظام الأقبة البلاستيكية) داخل المراكز الإدارية بمحافظة شمال سيناء خلال الفترة (2014-2016)

\begin{tabular}{|c|c|c|c|c|c|c|}
\hline الاجمالي & الحسنة & بئر العبد & الشيخ زويد & رفح & العريش & السنة \\
\hline 1417 & 0 & 404 & 217 & 153 & 643 & $\overline{2014}$ \\
\hline 3470 & 5 & 1220 & 569 & 478 & 1198 & 2015 \\
\hline 2268 & 0 & 911 & 551 & 538 & 538 & 2016 \\
\hline
\end{tabular}

1- مديرية الزر اعة بمحافظة شمال سيناء، بيانات ثانوية غير منشورة، أعداد متفرقة، 2017. 2- المر اقبة العامة للتعاون و التنمية والتوطين بمحافظة شمال سيناء، بيانات ثانوية غير منشورة، أعداءئنة أعداد متفرقة، 2017. جدول 2. تطور المساحات المنزرعة من محصول الكنتالوب الصيفي داخل المراكز الإدارية بمحافظة شمال سيناء خلال الفترة (2014-2016)

\begin{tabular}{|c|c|c|c|c|c|c|c|}
\hline الاجمالي & نخل & الحسنة & بئر العبد & الشيخ زويد & رفح & العريش & السنة \\
\hline 3370 & 0 & 0 & 1126 & 728 & 511 & 1005 & 2014 \\
\hline 3157 & 0 & 0 & 1077 & 691 & 384 & 1005 & 2015 \\
\hline 3150 & 0 & 5 & 1038 & 691 & 384 & 1032 & 2016 \\
\hline
\end{tabular}




\author{
المُلخص العربي \\ القياس الإحصائي لاوال إنتاج محصول الكانتلوب الشتوي والصيفي في محافظة شمال سيناء

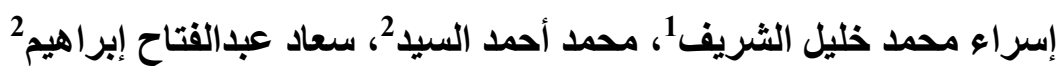

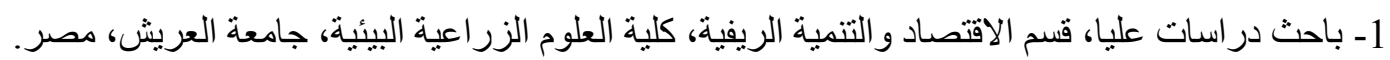 \\ 2- قسم الاقتصاد و التنمية الريفية، كلية العلوم الزر اعية البيئية، جامعة العريش، مصر.
}

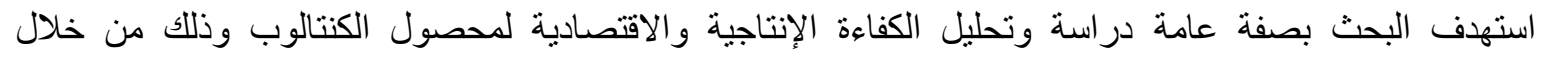

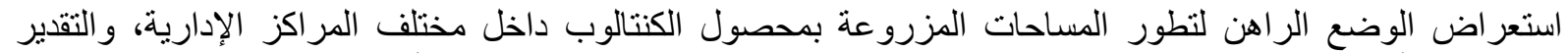

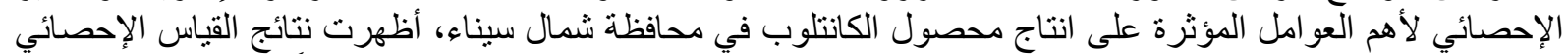

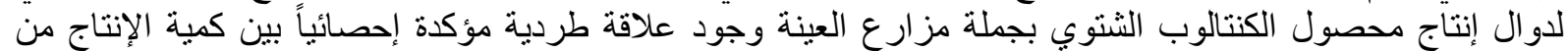

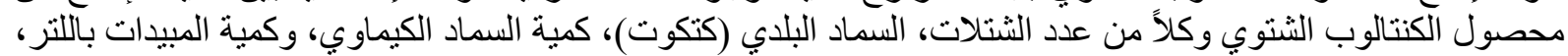

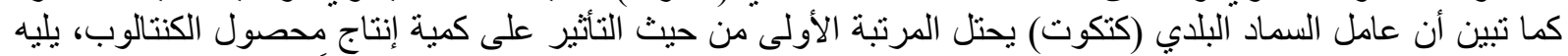

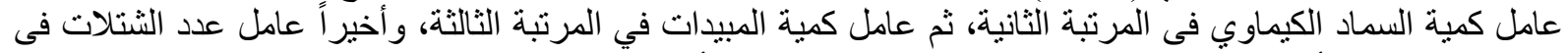

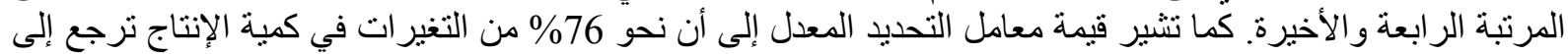

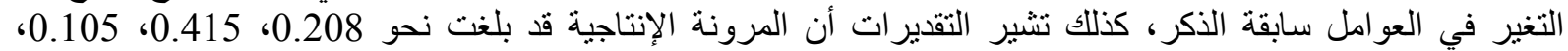

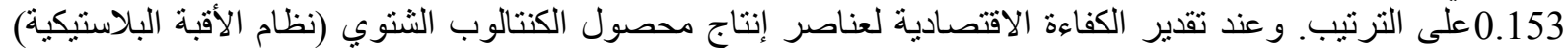

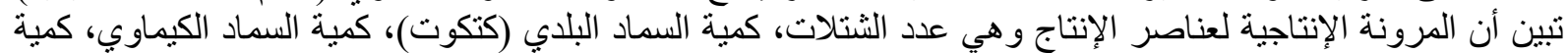

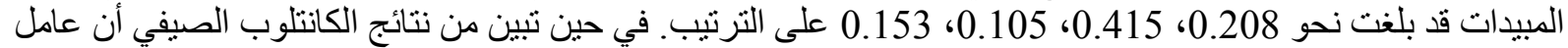

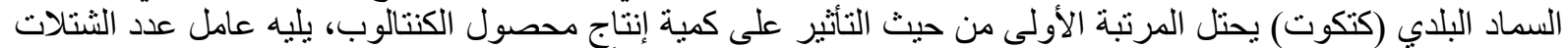

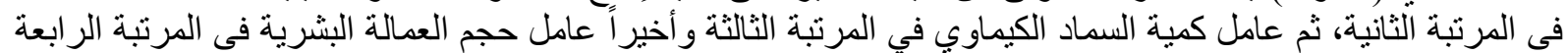

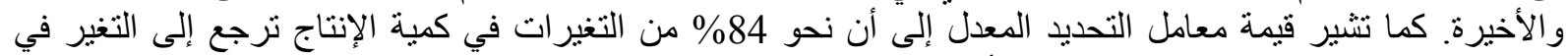

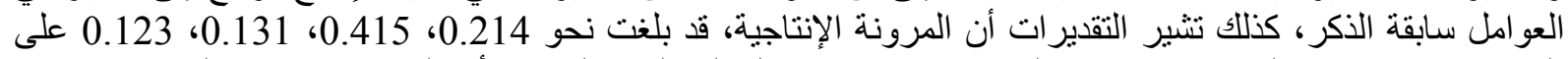

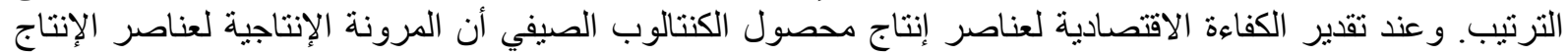

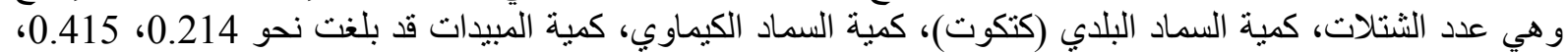

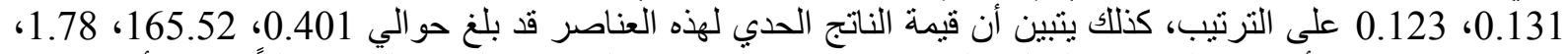

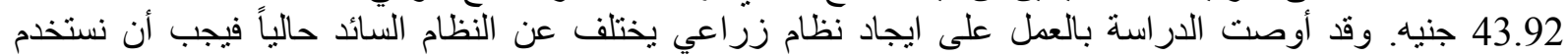

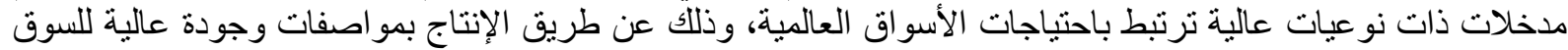
الخارجي. الكلمات الإسترشادية: محصول الكانتلوب، الكفاءة الانتاجية، دوال الانتاج، المرونة الإنتاجية.

أستاذ الاقتصاد الزر اعي، كلية الزر اعة، جامعة الزقازيق، مصر . أستاذ الاقتصاد الزراعي، كلية العلوم الزراعية الزعاعة البيئية، جامعة العريش، مصر، مصر.
المحكمــــــن أحمن

1- أ.د. أحمد فؤاد محمد مشهور 2- أ.د. رياض. أحم فوال مدماعيل رضوان مثهور 
